International Journal of Biological Research, $2(2)(2014) 78-80$
International Journal of Biological Research
Journal home page: $\begin{gathered}\text { www.sciencepubco.com/index.php/IJBR } \\ \text { doi: } 10.14419 / \text { ijbr.v2i2.2988 } \\ \text { Research Paper }\end{gathered}$

\title{
Corelation between glucose level, lipid profile and risk of coronary heart disease associated with organophosphorus pesticide poisoning
}

\author{
Kale Bhagwat \\ Department of Biochemistry Pandit Deendayal Upadhyay Dental, Solapur \\ E-mail: bhagwatkale2644@rediffmail.com
}

\begin{abstract}
The aim of our research was to correlate blood glucose and serum lipid profile parameters with risk of coronary heart disease associated with organophosphorus pesticide poisoning. For the purpose of this, 50 patients of organophosphorus poisoning and 50 healthy controls were selected. Blood glucose and serum lipid profiles were estimated by using commercially available diagnostic kits. We found a significant decrease $(\mathrm{p}<0.05)$ in serum TAG, serum HDL cholesterol and serum VLDL cholesterol. On other hand we found a significant increase $(\mathrm{p}<0.05)$ in blood glucose, serum total cholesterol and serum VLDL cholesterol. Organophosphorus poisoning is also associated with increased free radical production. Free radicals oxidize LDL cholesterol and oxidized cholesterol is taken by macrophages to form foam cells. Foam cells are responsible for formation of atherosclerotic plaques. Such plaques reduce coronary artery lumen and thus blood supply to heart get reduced which enhances the chances of myocardial infarction. Here, decreased HDL and VLDL and increased LDL cholesterol in organophosphorus poisoning is associated with increased risk of coronary heart diseases. Hence, estimation of blood glucose and lipid profile play important role in the diagnosis of risk of coronary heart diseases in organophosphorus poisoning.
\end{abstract}

Keywords: Organophosphorus, Acetyl cholinesterase, Lipid Profile, Acetylcholine, Glucose.

\section{Introduction}

India is basically an agricultural country. Nearly $70 \%$ of its population lives in rural areas. The primary occupation of the rural population is agriculture. A diverse group of agro-chemicals is indiscriminately sprayed by farmers for pest control to save the crops. The agrochemicals are popularly known as pesticides which have been broadly classified into organophosphorus pesticides, organochlorine pesticides, carbamates, pyrethroids etc. The commonly sprayed pesticides are organophosphorus pesticides which are very powerful neurotoxins resulting in neurotoxicity on acute or chronic exposure.(James 2003, Haque et.al. 2012) Pests are the animals or plants which are harmful to the interest of human beings. The term pest includes insects, rodents, nematodes, fungi, bacteria, weeds and various parasitic plants. Viruses and disease causing microorganisms not belongs to this category.(Ubale 2007) A pesticide is a substance or mixture of substances used to kill a pest. The term pesticide is defined as, any substance or mixture of substances intended for preventing, destroying or controlling any pest, including vectors of human or animal disease, unwanted species of plants or animals interfering with the production, processing, storage, transport or marketing of food, agricultural commodities, wood and wood products or animal feedstuffs. (Ellenhorn 1997).

The term pesticides include insecticides, herbicides, fungicides, rodenticides and disinfectants. A pesticide may be a liquid (mist or spray), solid (dust, granule or bait) or gas (vapour) applied to control unwanted insects, ticks, mites, plants or animals in a given area. (James 2003)

Pesticide poisonings remain a serious public health problem worldwide. According to the World Health Organization's estimate, 30, 00,000 cases of pesticide poisoning occur every year, resulting in more than 2, 50,000 deaths. Among the numerous pesticides that can result in death, organophosphate insecticides are the most common culprit agents because of their high toxicity. (Satoh et.al. 1999, Inayat-Hussain et.al. 2007)

Organophosphate (OP) insecticides are potent inhibitors of acetyl cholinesterase enzyme. This inhibition leads to an increase in acetylcholine activity, which is responsible for symptoms seen in organophosphorus poisoning such as abdominal pain, diarrhea, hyper-sialorrhea and vomiting. The primary mechanism of action of organophosphorus pesticides is based on inhibition of the acetylcholinesterase (AChE) enzyme. Once acetylcholinesterase has been inactivated, acetylcholine ( $\mathrm{ACh}$ ) accumulates in the nervous system, resulting in overstimulation of muscarinic and nicotinic receptors which are associated with severe symptoms of poisoning. (Mason 2000, Fujikawa et.al. 2005, Roshini et.al. 2005).

Level of acetylcholinesterase inhibition and severity of poisoning symptoms in human's increases with increased pesticide doses, exposure time and atmospheric temperature. Thus, a progressive decrease in acetylcholinesterase activity is proportional to increase in severity of poisoning which reflects proportionate amount of pesticide consumed and absorbed in the body. (Lee et.al. 2001, Patil et.al. 2003). 
Acetyl cholinesterase is already well known marker for organophosphorus poisoning in humans. But, our interest was to known the changes occurring in the blood glucose and serum lipids. There is no study yet which shows correlation of blood glucose and serum lipids with severity of poisoning.

Hence in our research, we have tried to show correlation of blood glucose and serum lipids with severity of organophosphorus poisoning.

\section{Materials and methods}

$5 \mathrm{ml}$ of venous blood samples were collected in a plain bulb from 50 patients of organophosphorus poisoning for the study from various hospitals in the solapur city during period Jan -2010 to Oct - 2012. The blood sample was collected after the diagnosis of patient for organophosphorus poisoning in hospital. The blood samples for the controls $(n=50)$ were collected from the healthy volunteers. The obtained blood was centrifuged at $3000 \mathrm{rpm}$ for 15 minutes. The serum were collected and used for assay. For estimation of glucose, $2-3 \mathrm{ml}$ venous blood from the patient was collected. It was mixed suddenly with 1-2 drops of anticoagulant (potassium oxalate) and sodium fluoride. Finally, it was centrifuged at $3000 \mathrm{rpm}$ for 5 minutes and the plasma was collected for test. The biochemical parameters and methods to be used for their estimations were as follows:
Estimation of lipid profile: Total and HDL cholesterol is determined by cholesterol oxidase - peroxidase method. Triacylglycerol is determined by glycerol-3-oxidase - peroxidase method. LDL and VLDL cholesterol are determined from calculation. For estimation of Total and HDL cholesterol and Triacylglycerol a commercial kit obtained from starchem is used.

Estimation of glucose: Glucose is estimated by glucose oxidase peroxidase method. Glucose oxidase oxidizes glucose to gluconic acid and hydrogen peroxide. Peroxidase then act on liberated hydrogen peroxide and forms water and nascent oxygen. Nascent oxygen then couples with 4-amino antipyrine and phenol to form red coloured quinoneimine complex. The intensity of colour produced is directly proportional to concentration of glucose which is measured at $530 \mathrm{~nm}$ and compared to that of standard treated similarly.

\section{Results and discussion}

A present study includes 50 organophosphorus poisoned patients. The distribution of organophosphorus poisoned patients into five grades as very mild poisoned patients, mild poisoned patients, moderate poisoned patients, severe poisoned patients and highly severe poisoned patients were done according to percent inhibition of acetyl cholinesterase activity and criteria of World Health Organization (WHO).(Table 1)

Table 1: Distribution of Patients According to Severity of Poisoning on the Basis of who's Criteria and Symptoms Shown by Patients

\begin{tabular}{|c|c|c|c|c|}
\hline Group & $\begin{array}{l}\text { Grade } \\
\text { of poisoning }\end{array}$ & Symptoms & $\begin{array}{l}\text { Inhibition of acetyl cholinesterase activity in terms of } \\
\text { percentage }\end{array}$ & $\begin{array}{l}\text { No. of } \\
\text { cases }\end{array}$ \\
\hline I & Very Mild & \multirow{2}{*}{ Nausea, vomiting, diarrhea, sweating } & Less than $20 \%$ & 09 \\
\hline II & Mild & & More than $20 \%$ but less than $40 \%$ & 12 \\
\hline IV & Severe & \multirow{2}{*}{$\begin{array}{l}\text { Incontinence, apnoeic spells, ARDS, areflexia seizures, } \\
\text { coma etc. }\end{array}$} & More than $60 \%$ but less than $80 \%$ & 10 \\
\hline V & $\begin{array}{l}\text { Highly Se- } \\
\text { vere }\end{array}$ & & More than $80 \%$ & 07 \\
\hline
\end{tabular}

Table 2: Showing Comparative Values of Glucose in Healthy Controls and in Test (Organophosphorus Poisoning Patients)

\begin{tabular}{llllll}
\hline Biochemical parameters & Control $(\mathrm{N}=30)$ & Group I & Group II & Group III & Group IV \\
\hline $\begin{array}{l}\text { Blood glucose (Random) } \\
\mathrm{mg} / \mathrm{dl}\end{array}$ & $113.62 \pm 22.32$ & $129.34 \pm 19.18$ & $135.46 \pm 20.48$ & $147.86 \pm 24.68$ & $159.13 \pm 22.73$ \\
\hline
\end{tabular}

Table 3: Showing Comparative Values of Lipid Profile in Healthy Controls and in Test (Organophosphorus Poisoning Patients)

\begin{tabular}{|c|c|c|c|c|c|c|}
\hline Biochemical parameters & Control $(\mathrm{N}=30)$ & Group I & Group II & Group III & Group IV & Group V \\
\hline Triacylglycerol (mg/dl) & $138.77 \pm 13.46$ & $136.93 \pm 13.74$ & $131.23 \pm 12.84$ & $129.87 \pm 12.53$ & $122.59 \pm 10.26$ & $116.42 \pm 12.65$ \\
\hline Total cholesterol (mg/dl) & $222.28 \pm 23.86$ & $238.96 \pm 26.71$ & $257.37 \pm 27.69$ & $269.19 \pm 26.39$ & $281.63 \pm 29.41$ & $295.45 \pm 31.94$ \\
\hline HDL cholesterol (mg/dl) & $38.96 \pm 7.84$ & $37.25 \pm 7.68$ & $36.68 \pm 6.86$ & $29.22 \pm 6.97$ & $27.67 \pm 6.64$ & $22.87 \pm 5.78$ \\
\hline LDL cholesterol (mg/dl) & $117.36 \pm 11.32$ & $123.95 \pm 19.68$ & $131.62 \pm 19.23$ & $136.56 \pm 18.89$ & $143.47 \pm 22.41$ & $159.63 \pm 23.03$ \\
\hline VLDL cholesterol $(\mathrm{mg} / \mathrm{dl})$ & $19.35 \pm 1.46$ & $17.22 \pm 1.68$ & $15.84 \pm 1.41$ & $14.96 \pm 1.39$ & $13.98 \pm 1.23$ & $10.35 \pm 1.06$ \\
\hline
\end{tabular}

In our study, 37 cases of poisoning were found as a result of suicidal attempts while 13 due to accidental events. It is found that organophosphorus pesticide; dimethoate is more commonly used to attempt suicide as it is easily available. Majority of poisoning cases were due to dimethoate. The other cases of poisoning were due to sumethrine, parathion, deltanuthrin, malathion, cypermethrin, chlorpyriphos, tick - 20 etc. Out of 50 patients studied by us, 41 get cured while 09 patients got expired. The death generally occurred due to respiratory failure.

In our study we have estimated blood glucose level and lipid profile level in organophosphorus poisoning. We found a significant increase $(\mathrm{p}<0.05)$ in blood glucose level with severity of poisoning. (Table 2) The hyperglycemia is seen in organophosphorus poisoning because of following mechanism. Organophosphorus poisoning result in inhibition of enzyme acetyl cholinesterase. Inhibition of acetyl cholinesterase causes accumulation of acetylcholine which further causes hyper stimulation of acetylcholine receptors. This is associated with excessive secretion of adrenocorticotropic hormone (ACTH). ACTH stimulates adrenal gland to secrete catecholamines. Increased catecholamines causes excessive breakdown of stored glycogen and hence causes increase in blood glucose level.
When estimated triacylglycerol (TAG), we found a significant decrease $(\mathrm{p}<0.05)$ in its level in organophosphorus poisoning. (Table 3). This is because organophosphorus poisoning causes liver damage. This is associated with reduced fatty acid synthesis and thus TAG synthesis is reduced that leads to its reduction in serum. Further excess catecholamines production triggers adenylate cyclase. Thus, cAMP level increases which then activate cAMP dependent protein kinase. cAMP dependent protein kinase then phosphorylates and activates TAG lipase enzyme. Activated lipase enhances breakdown of TAG.

Serum total cholesterol is found increased significantly $(p<0.05)$. This is due to liver damage. Damaged lived cannot secrete bile juice in the duodenum. Thus, release of cholesterol in the duodenum via bile juice is prevented which causes increase in its serum level. (Table 3).

Very low density lipoprotein (VLDL) cholesterol decreases significantly $(\mathrm{p}<0.05$ ) because of following reasons. First upon TAG synthesis and TAG level is reduced which causes reduction in incorporation of TAG to form VLDL cholesterol. Secondly, increased cholesterol enhances its incorporation in VLDL and turn it into LDL cholesterol. This causes significant $(\mathrm{p}<0.05)$ increase in LDL cholesterol level but decrease in VLDL cholesterol level in serum. Further the increased lipase activity is also responsible 
for catabolism of HDL and VLDL cholesterol. This causes significant reduction $(\mathrm{p}<0.05)$ in both HDL and VLDL cholesterol levels. (Table 3).

Organophosphorus poisoning is associated with decreased antioxidants. Hence, free radical formation is enhanced in organophosphorus poisoning. These free radicals enhance oxidation of LDL cholesterol which is already high. Now, these oxidized LDL molecules is taken by macrophages and thus macrophages get converted to foam cells. These foam cells get trapped in the walls of blood vessels and causes formation of atherosclerotic plaques. Thus, lumen of blood vessels becomes narrow cause's reduction in blood flow. If this event occurs in coronary artery then blood supply to heart get reduced which enhances the chances of myocardial infarction. Thus, decreased HDL and VLDL and increased LDL cholesterol in organophosphorus poisoning is associated with increased risk of coronary heart diseases. Hence, estimation of blood glucose and lipid profile play important role in the diagnosis of risk of coronary heart diseases in organophosphorus poisoning.

\section{Conclusion}

In our research study, we found a significant decrease in serum TAG, serum HDL cholesterol and serum VLDL cholesterol. On other hand we found a significant increase in blood glucose, serum total cholesterol and serum VLDL cholesterol. Organophosphorus poisoning is also associated with increased free radical production. Free radicals oxidize LDL cholesterol and oxidized cholesterol is taken by macrophages to form foam cells. Foam cells are responsible for formation of atherosclerotic plaques. Such plaques reduce coronary artery lumen and thus blood supply to heart get reduced which enhances the chances of myocardial infarction. Here, decreased HDL and VLDL and increased LDL cholesterol in organophosphorus poisoning is associated with increased risk of coronary heart diseases. Hence, estimation of blood glucose and lipid profile play important role in the diagnosis of risk of coronary heart diseases in organophosphorus poisoning.

\section{Acknowledgment}

We would like to thank the Biochemistry Department of V. M. Medical College, Solapur. We are also indebted to all the patients and our colleagues for their co-operation in this research.

\section{References}

[1] Ellenhorn M, Schonwald S, Ordog G, Wasserberger J. Ellen-horn's Medical Toxicology: Diagnosis and Treatment of Human Poisoning, Williams \& Wilkins 4th edition, (1997):1614-63.

[2] Fujikawa Y, Satoh T, Suganuma $S$ et al. Extremely sensitive biomarker of acute organophosphorus insecticide exposure. Hum Exp Toxicol; $\quad 24 \quad$ (2005): $\quad 333-336$. http://dx.doi.org/10.1191/0960327105ht532oa.

[3] Haque Q, Jamal F, Rastogi S (2012). Effect of organophosphorus on biochemical parameters on agriculture workers on mango orchards $\begin{array}{lllll}\text { Asian J } & \text { Biochemistry, } & 7 & \text { (1): }\end{array}$ http://dx.doi.org/10.3923/ajb.2012.37.45.

[4] Inayat-Hussain $\mathrm{SH}$, Lubis $\mathrm{SH}$, Sakian NI et al. Is plasma betaglucuronidase a novel human biomarker for monitoring anticholinesterase pesticides exposure? A Malaysian experience. Toxicol Appl Pharmacol; 219 (2007): 210-216. http://dx.doi.org/10.1016/j.taap.2006.10.014.

[5] James L (2003). How to prevent and treat pesticide poison-ing.NSW agriculture; $1-3$.

[6] James L. How to prevent and treat pesticide poisoning. NSW agriculture, (2003):1-3.

[7] Lee P, Tai DYH. Clinical features of patients with acute organophosphate poisoning requiring intensive care. Intensive Care Med; 27 (2001):69. http://dx.doi.org/10.1007/s001340100895.

[8] Mason H J. The recovery of plasma cholinesterase and erythro-cyte acetylcholinesterase activity in workers after overexposure to dichlorvos. Occup. Med (Lond.); 50 (2000): 343-347. http://dx.doi.org/10.1093/occmed/50.5.343.

[9] Patil J, Patil a et al. Biochemical effects of various pesticides on sprayers of grape gardens. Ind J Clin Biochem; 18/2 (2003):16-22. http://dx.doi.org/10.1007/BF02867362

[10]Roshini C, Visalakshi. Biochemical and clinical profile after organophosphorus are poisoning-A plasebo-controlled trial using pralidoxime. J Assoc Physicians India; 53 (2005):422-4.

[11]Satoh T, Suzuki S, Kawai N, Nakamura T, Hosokawa M. Toxicological significance in the cleavage of esterase-beta-glucuronidase complex in liver microsomes by organophosphorus compounds. Chem Biol Interact; 119 (1999): 471-478. http://dx.doi.org/10.1016/S00092797 (99)00060-5.

[12]Ubale V et al. Text book of organic chemistry B.Sc.-part III, Paper VII 2nd edition (2007):10.1-15. 